\title{
Pedagogia e complexidade: diálogos preliminares
}

\section{Pedagogy and complexity: preliminary dialogues}

\author{
Ricardo Antunes de Sá
}

\begin{abstract}
RESUMO
$\mathrm{O}$ artigo tem a intenção de apresentar argumentações fundamentadas em estudos de pesquisadores que têm procurado identificar a Pedagogia como uma das áreas das ciências do homem que estuda e produz conhecimento científico sobre o fenômeno educativo. Em um primeiro momento apresenta, sucintamente, os pressupostos teóricos norteadores da teoria da complexidade, sistematizada por Edgar Morin. Por fim, ensaia-se um diálogo preliminar entre os pressupostos do pensamento complexo e a Pedagogia.
\end{abstract}

Palavras-chave: educação; pedagogia; complexidade; ciência pedagógica.

\begin{abstract}
The article has the intention of presenting arguments based on studies by researchers who have sought to identify education as one of the areas of science that studies the human and produces scientific knowledge about the educational phenomenon. Currently below shows, briefly, the theoretical assumptions guiding the theory of complexity, systematized by Edgar Morin. Finally, tests to a preliminary dialogue between the assumptions of complex thought and Pedagogy.
\end{abstract}

Keywords: education; teaching; complexity; science teaching.

* Professor Adjunto I do Setor de Educação da Universidade Federal do Paraná - UFPR. Mestre em Educação pela UFPR. Doutor em Educação pela UNICAMP. Correio eletrônico: antunesdesa@gmail.com 


\section{Introdução}

Nas últimas décadas do século XX e nos anos iniciais do XXI, a formação de professores tem sido influenciada pela complexidade da alta modernidade (GIDDENS, 2002). As transformações ocorridas no mundo da ciência (paradigmas emergentes); a incorporação da tecnologia da informação e da comunicação aos processos de formação e qualificação humanas; as relações sociais que se configuram num emaranhado de novos atores e personagens que pleiteiam seus direitos, frente ao Estado; os processos de organização e produção flexível das mercadorias; a globalização econômica e as contradições do capitalismo; a complexificação das relações familiares e culturais e a ambivalente influência das mídias sobre os processos de disseminação da informação sobre a sociedade mundializada têm trazido novas questões e debates sobre a formação de professores e, em especial, sobre a formação do pedagogo.

A questão da cientificidade da Pedagogia tem sido estudada por vários pesquisadores e teóricos da educação que atuam em universidades européias e brasileiras nos últimos anos. Acredita-se que hoje, em pleno século XXI, a questão epistemológica da Pedagogia, ciência ${ }^{1}$ que estuda e elabora um conhecimento científico específico sobre o fenômeno educativo, venha se consolidando e se diferenciando no tocante à especificidade do conhecimento pedagógico em relação às demais ciências do homem que se debruçam sobre a educação no âmbito acadêmico.

\section{Pedagogia: uma ciência em construção...}

Dentro do universo que envolve a formação de professores no Brasil, o curso de Pedagogia ${ }^{2}$ tem uma longa história de contribuição à formação de

1 Etimologicamente falando, ciência vem do latim (scientia) e significa conhecimento, sabedoria. A ciência é uma narrativa que se manifesta com base em um corpo de princípios, de teorias organizadas metódica e sistematicamente, construindo uma área do saber humano, relativa a um fenômeno ou objeto de estudo. A ciência não é acumulação de "verdades" mas um campo aberto onde se degladiam as teorias, os princípios e as concepções de mundo (MORIN, 2001b).

2 Conforme Ferreira (1986, p.1290), a Pedagogia é: "Teoria e ciência da educação e do ensino. Conjunto de doutrinas, princípios e métodos de educação e instrução que tendem a um objetivo prático. O estudo dos ideais de educação, segundo uma determinada concepção de vida, e dos meios (processos e técnicas) mais eficientes para efetivar estes ideais". 
técnicos e licenciados para a educação brasileira nesses últimos 69 anos. Vários pesquisadores, professores e pedagogos (BRZEZINSKI, 1996; PIMENTA, 1996, 2002, 2007; FRANCO, 2003; LIBÂNEO, 1996, 1998, 2006, 2007; SILVA, 1999; SA, 1997, 2000, 2006; HOUSSAYE et al., 2004) têm enfrentado esse debate acadêmico, pesquisado e sistematizado conhecimentos a respeito da demarcação epistemológica da Pedagogia, considerada uma ciência aplicada (FREITAS, 1985) que busca gerar uma Teoria Pedagógica, um conhecimento pedagógico consistente, coerente e conseqüente com reflexos para a identidade profissional do pedagogo.

Sendo a Pedagogia uma ciência aplicada da e para a prática educativa (SCHMIED-KOWARZIK, 1983), seu objeto de estudo é a educação (escolar e não-escolar). Conforme indicação de Libâneo (2007, p.17): “[...] a pedagogia é o campo científico que faz uma reflexão sistemática sobre a prática educativa, a educação, que é o objeto de estudo da pedagogia".

A educação por sua vez é um fenômeno humano: histórico, inconcluso, movente, contraditório, ambivalente etc., o que exige por parte da Pedagogia a elaboração de um discurso próprio; da construção de categorias específicas de análise do fenômeno educativo a partir das contribuições de outras ciências que se debruçam sobre os processos de formação humana. A produção do conhecimento específico da Pedagogia não se confunde com os discursos das ciências que lhe dão suporte.

Sobre a colaboração das ciências que contribuem para a construção do discurso pedagógico, Pimenta (1996) sistematiza esse entendimento à medida que argumenta que quando um psicólogo trabalha no campo educacional, ele não faz pedagogia, mas aplica os conceitos e métodos próprios da psicologia para analisar e intervir no espaço educativo.

Certamente a Psicologia, a Sociologia ou a Economia ocupam-se de problemas educativos, todavia essas ciências abordam o fenômeno educativo (escolar e não-escolar) sob a ótica de seus olhares epistemológicos. Como diz Franco et al. (2007, p.79):

É a Pedagogia que pode requerer para si a investigação do campo educativo propriamente dito, como também de seus desdobramentos práticos, e com isso constitui-se em conhecimento integrador dos aportes das demais áreas

A Resolução n.1/2006 - CNE/CP, de 15 de maio de 2006, que instituiu as Diretrizes Curriculares Nacionais (BRASIL, 2006), no artigo $2^{\circ}$, parágrafo $2^{\circ}$, 
item II, evidencia que a Pedagogia enquanto área do conhecimento que estuda o fenômeno educativo necessita da contribuição de outras áreas do conhecimento como: "[...] filosófico, histórico, antropológico, ambiental-ecológico, psicológico, o lingüístico, o sociológico, o político, o econômico, o cultural". Isso traduz a compreensão de que a Pedagogia é uma ciência aplicada, o que significa que ela se apóia na contribuição de outras epistemes para poder elaborar seu discurso científico.

No artigo $5^{\circ}$ da Resolução n. 01/2006, no item XV (BRASIL, 2006), é possível perceber a indicação do legislador quanto à utilização de instrumentos próprios da Pedagogia na construção de conhecimentos pedagógicos e científicos, o que demonstra que a Pedagogia, embora incorpore contribuições epistemológicas das áreas do conhecimento humano, constrói um conhecimento com identidade própria.

A Pedagogia do ponto de vista do princípio sistêmico-organizacional (MORIN, 2005a) poderia ser compreendida como um todo, como a emergência, como o produto das inter-relações e das interações dos aportes epistemológicos das outras áreas do conhecimento científico que, dinamicamente, contribuem para a síntese integradora sistematizada pela Pedagogia. Diria-se que o todo (o discurso pedagógico) não se confunde com as partes (aportes das demais ciências). No entanto, um não acontece sem a colaboração do outro. $\mathrm{O}$ todo não é a soma das partes.

O que se depreende é que a pedagogia enquanto produtora de conhecimento científico sobre a realidade educativa, procura, para contemplar os requisitos de cientificidade do discurso, procedimentos metodológicos que: observem, descrevam, comparem, analisem, confrontem e sistematizem os dados fenomênicos do real pedagógico (PIMENTA, 1996) para, então, poder tecer, elaborar, produzir um conhecimento especificamente pedagógico.

Cabe à pedagogia a preocupação com a objetividade do conhecimento, tendo em vista que:

[...] a objetividade parece ser uma condição sine qua non evidente e absoluta de todo o conhecimento científico. A objetividade é uma coisa absolutamente certa. Ela é determinada por observação e verificações concordantes [...] objetividade é o resultado de um processo crítico desenvolvido por uma comunidade/sociedade científica num jogo em que ela assume plenamente as regras (MORIN, 2001b, p. 40-42).

Então como se pode caracterizar o conhecimento científico da Pedagogia 
para além da arte e da técnica, simplesmente? Ora, é preciso um método científico que lhe possibilite captar a dimensão pedagógica implícita em todos os processos educativos (escolares e não-escolares). Os processos educativos escolares envolvem sempre: os estudantes e o processo de aprendizagem, os docentes e o processo de ensino, a instituição escolar, a gestão pedagógico-administrativa, as instâncias coletivas de deliberação (conselho de classe, conselho de escola), o projeto político-pedagógico e etc.

O conhecimento científico elaborado a partir da dimensão pedagógica implícita nos processos educativos, que são atividades históricas, complexas e dinâmicas, se constrói a partir da sua descrição, análise, explicação, interpretação e sistematização de uma narrativa pedagógica que contempla o diálogo entre os aportes epistemológicos das demais ciências do homem e a dimensão pedagógica implícita na práxis educativa estudada.

Considerada a Pedagogia uma das ciências humanas, tendo em vista sua historicidade e provisoriedade enquanto conhecimento teórico que sempre é revisitado pelo confronto dialético e dialógico com a realidade, depara-se, hoje, com uma complexa sociedade na qual seu campo específico de estudo: os processos educativos se conformam e/ou deformam frente às transformações societárias, econômicas, culturais, políticas e tecno-científicas ocorridas ao longo do século XX.

Vários autores e pesquisadores (MORAES, 1997, 2004a, 2004b; PETRÁGLIA, 2005; CARVALHO, 2003; BEHRENS, 2006; CAPRA, 2002; MORIN, 2005a, 2005b) têm evidenciado a necessidade de se rever os paradigmas científicos da Modernidade (MORIN, 2002b), tendo em vista as profundas transformações epistemológicas trazidas pelas ciências que estudam a respeito do homem, da Terra e do macrouniverso (ciências da Terra, da Cosmologia e da Ecologia) e do microuniverso (física quântica). A teoria da complexidade que procurará de alguma forma organizar, sistematizar e articular um diálogo com os novos paradigmas emergentes (MORAES, 1997) das ciências. O fenômeno complexo "[...] é imposto pelo real e que não pode ser rejeitado" (MORIN, 1993, p.87).

Entende-se que a ciência pedagógica compreendida aqui como Pedagogia deve se inscrever neste debate, no sentido de estabelecer um diálogo teórico e metodológico com os pressupostos que vêm trazendo a teoria da complexidade para a ciência e para a educação. 


\section{Olhares da teoria da complexidade}

A Teoria da Complexidade sistematizada por Edgar Morin ${ }^{3}$ procura tecer a construção de um conhecimento capaz de religar os saberes com o intuito de superar o pensamento disjuntivo, reducionista ${ }^{4}$ e linear, produzido pela ciência da Modernidade. Procura também superar a visão fragmentada do universo, buscando uma reaproximação das partes para reconstituir o todo nas várias áreas do conhecimento (BEHRENS, 2006).

Sua produção intelectual (MORIN,1993; 2001a; 2001b; 2002a; 2002b; 2005a; 2005b) vem se aprimorando desde os anos cinqüenta do século passado no sentido de construir um método que possa rejuntar, articular e fazer com que as ciências naturais e humanas possam dialogar. Suas idéias se traduzem numa síntese aberta e inacabada, porém radical no que tange ao papel social e ético da ciência e da educação (ALMEIDA, 2005).

Rodrigues (2003) ressalta que os estudos desse sociólogo francês certamente repercutirão na educação e nos currículos escolares à medida que propõem uma mudança paradigmática que contemple a articulação dos conhecimentos, questionando as teorias que se fecham para o diálogo, para a incerteza, permitindo contestar as próprias estruturas já estabelecidas, abrindo possibilidades inusitadas e corajosas na busca de conhecer a teia, a trama complexa do real.

O pensar complexo significa compreender cientificamente a interdependência e interconexão entre todos os fenômenos físicos, naturais e sociais. O pensamento complexo procura superar uma visão linear, reducionista e disjuntiva do conhecimento, do processo de (re)construção dos saberes científicos. O verdadeiro problema da reforma do pensamento, como diz Morin (2001a), é que se aprendeu a separar, mas é preciso (re)aprender a (re)ligar, estabelecer uma conexão completa que faça um círculo completo.

Conforme Petráglia (2005), o termo complexidade surgiu na obra de Morin no final dos anos 1960, advindo da Teoria dos Sistemas, da Cibernética e do conceito de auto-organização. Complexo vem do latim (complexus) e quer dizer um conjunto de coisas, fatos, circunstâncias, eventos que apresentam ligação e

3 Em tempo, é importante deixar claro que a produção científica desse intelectual é vastíssima, percorrendo diversas e diferentes temáticas, sob o mesmo Método. Pretende-se, apenas, demarcar alguns elementos teóricos e metodológicos importantes do pensamento complexo que auxiliaram nos diálogos preliminares com a Pedagogia.

4 “O pensamento reducionista continua a procurar de modo míope a causa e o efeito, a determinar o Bem e o Mal, a nomear o culpado e o salvador. Continua eliminar toda ambigüidade, toda a incerteza [...]" (MORIN, 2002a, p.112). 
são interdependentes. São partícipes de um todo (sistema), o que equivale a dizer que esse todo se torna uma unidade complexa. "[...] identifica-se com tudo aquilo que se tece em conjunto, que reassocia o que está dissociado, comunica o que está incomunicável, religa o que está separado" (CARVALHO, 2003, p.97).

Complexidade é a trama dos acontecimentos, das ações, das interações, das retroações, das determinações, dos acasos que constituem nosso mundo fenomênico (MORIN, 2005a). Entende a incerteza e as contradições como parte da vida e da condição do homem na terra e, ao mesmo tempo, sugere Morin a solidariedade e a ética como caminho para a (re)ligação dos seres e dos saberes (PETRÁGLIA, 2005).

Morin (2001a, p.25) cita, recorrentemente, para fundamentar paradigmaticamente a construção do pensar de maneira complexa, a reflexão de Blaise Pascal (1623 - 1662) quando afirma que:

Sendo todas as coisas causadas e causadoras, ajudadas, mediatas e imediatas, e todas elas mantidas por um elo natural e insensível, que interliga as mais distantes e as mais diferentes, considero impossível conhecer as partes sem conhecer o todo, assim como conhecer o todo sem conhecer, particularmente, as partes [...].

Os fenômenos naturais, físicos, sociais, educacionais se manifestam nas ações integradas, de inter-retroações entre cada uma dessas dimensões e seu contexto. São as relações de reciprocidade, de tensionamento que possibilitam verificar como uma modificação do todo repercute sobre as demais dimensões envolvidas, bem como de que forma as modificações nas dimensões repercutem no todo, no conjunto.

De acordo com Morin (2001a, p.25) trata-se de reconhecer a unidade dentro do diverso e o diverso dentro da unidade ou reconhecer, por exemplo, "[...] a unidade humana em meio às diversidades individuais e culturais e as diversidades individuais e culturais em meio à unidade humana".

Conceber a realidade de forma complexa exige uma interpretação que contemple as dimensões antagônicas e ambivalentes, sem, contudo, desconsiderar a multidimensionalidade 5 do real. Um pensamento que apreenda as relações, as inter-relações, as implicações mútuas, os fenômenos multidimensionais, as situações sistêmicas que são simultaneamente solidárias e conflitivas. A

5 As dimensões econômicas, biológicas, culturais, psicológicas, sociais, genéticas, educacionais, religiosas, ecológicas, antropológicas, tecnológicas, midiáticas e etc. 
democracia poderia ser compreendida como um sistema que se fundamenta no antagonismo de grupos sociais, mas ao mesmo tempo se auto-regula por meio de mecanismos de convencimento (ideologias) e/ou de coerção.

\section{Conceito de sistema e organização}

A conceituação de sistema vai mais além do que a soma das partes como já foi anteriormente referenciado. Um sistema apresenta qualidades, propriedades que não podem ser notadas no nível das partes isoladas. E nesse sentido, o todo será mais do que a soma das partes. Apresentará qualidades e propriedades distintas em relação às partes. Mas, por outro lado, dentro de um processo dinâmico e relacional, o todo pode inibir as qualidades e as propriedades das partes, o que fará com que o todo acabe ficando menor, qualitativamente falando, que a soma das partes que o compõem.

Para Carvalho, o sistema é uma unidade ambivalente, instável, no qual o todo e a parte por vezes se associam, por outras se dissociam, tendo em vista as imprevisibilidades, instabilidades e polidependências. Por outro lado, o sistema não pode ser uma totalidade fechada em relação ao seu entorno ou a outros sistemas porque isso faria com que estivesse condenado "[...] a ampliação da entropia, ao aumento da desordem sobre a ordem: à iminência do caos desorganizador, conforme prevê o segundo princípio da termodinâmica" (2003, p.99).

Um sistema ${ }^{6}$ apresenta qualidades e propriedades próprias. Estas qualidades só aparecem quando o sistema se constitui num processo dinâmico de interação e interdependência entre as partes. Essas qualidades e propriedades que emergem do todo, do sistema, retroagem sobre as partes. Pena-Vega et al. (2001, p.150) exemplifica dizendo que:

6 Sistema. [Do grego systema, reunião, grupo, pelo latim systema]. S.m. 1. Conjunto de elementos, materiais ou ideais, entre os quais se possa encontrar ou definir alguma relação. 2 . Disposição das partes ou dos elementos de um todo, coordenados entre si, e que funcionam como estrutura organizada: sistema penitenciário; sistema de refrigeração. 3. Reunião de elementos naturais da mesma espécie, que constituem um conjunto intimamente relacionado: sistema fluvial; sistema cristalino. 4. O conjunto das instituições políticas e/ou sociais, e dos métodos por elas adotados, encarados quer do ponto de vista teórico, quer do de sua aplicação prática: sistema parlamentar; sistema de ensino. 5. Reunião coordenada e lógica de princípios ou idéias relacionadas de modo que abranjam um campo do conhecimento: os sistemas de Kant; o sistema de Ptolomeu. 19. [...] (FERREIRA, 1986, p.1.594). 
[...] nós seres sociais, fazemos parte de uma sociedade, mas a sociedade só pode se constituir pelas interações entre os indivíduos que somos. Dessas interações nasceram qualidades emergentes, a cultura, a educação, e são elas que fazem de nós verdadeiros indivíduos. Ou seja, se não houvesse esta rotação dos indivíduos para a sociedade e da sociedade para os indivíduos, nós seríamos apenas primatas de última linha, nós não poderíamos desenvolver nossas qualidades individuais.

Como tudo se interdepende, se interconecta dinamicamente, é necessário que a esfera antropossocial se enraíze na esfera biológica porque somos seres vivos, animais vertebrados, mamíferos e primatas, mas também estamos ligados ao mundo físico-químico. Prigogine (2002) vai dizer que a complexidade biológica é fenomenal, mas que há também a complexidade das particularidades elementares da matéria que estão presentes em todo o universo.

Conforme Capra (2002, p. 267): Em todos os níveis de vida - desde as redes metabólicas dentro da célula até as teias alimentares dos ecossistemas e as redes de comunicações da sociedade humana, os componentes dos sistemas vivos se interligam sob a forma de rede. Em verdade nada consegue se manter isolado, embora sejam mantidas sempre as identidades e as individualidades de cada organização sistêmica e de suas partes.

O sistema só se constitui quando existe organização e interação entre os elementos constituintes. A relação entre o todo, a totalidade sistêmica e as suas partes é mediada por interações. É o conjunto dessas interações entre as partes in acto que gera uma organização que molda e configura sua estrutura interna. A organização dá coerência, regula, mantém, protege, rege o sistema, enquanto as interações exprimem o conjunto de relações, ações e retroações que se manifestam e se desenvolvem dentro de um sistema (MORIN, 2001b).

A organização cria ordem, dinamiza, armazena, reparte, controla fluxos de energia, organiza as interações internas com o meio ambiente. Nessa dinâmica, acaba gastando, despendendo energia, o que gera nos organismos processos de degradação, de entropia (desordem). Ao mesmo tempo, pelo princípio da autoorganização, o organismo autogera mecanismos de (re)organização a fim de manter-se vivo, de restabelecer o equilíbrio dinâmico. Há uma dialógica entre a ordem e a desordem, entre processos agregadores e desagregadores, que em verdade são dimensões antagônicas e complementares indissociáveis existentes em qualquer sistema.

Embora paradoxal, a dialógica entre ordem e desordem é que mantém um equilíbrio dinâmico por meio das interações (internas e externas) de todo o sistema, mantendo ou alterando suas qualidades e propriedades. A desordem 
representaria os acasos, os choques, as imprevisibilidades, as desintegrações, as agitações, as turbulências, as degradações.

Nessa dinâmica relacional entre o sistema, organização e interação, criamse emergências, ou seja, qualidades ou propriedades que se manifestam ao nível do todo. As qualidades ou propriedades das partes dentro de um sistema não aparecem ou não existem quando essas partes são vistas isoladas do todo. Só podem ser percebidas ou desveladas pelo e no todo.

As qualidades das partes permanecem em estado de potência, virtuais, assim como num time de futebol, no qual os jogadores, tomados isoladamente, são apenas "craques" da bola. Somente no jogo, na ação é que essas potencialidades, interagindo entre si, poderão levar o time a vencer ou não o adversário. As qualidades e as propriedades das partes tornam-se reais quando estiverem inter-relacionadas dinamicamente ao todo, ao sistema.

A organização sistêmica, ao estabelecer-se mediante as retro-inter-relações das partes com o todo e deste com as partes, constrói um processo de autonomia, à medida que a organização se nutre de matéria, energia e informação do ambiente externo para poder existir, assegurando ao sistema uma relativa autonomia em relação a fatores aleatórios, inesperados ou incertos provenientes dessa relação com o exterior (MORIN, 1993).

\section{Princípios do pensamento complexo}

O pensamento complexo procura edificar um método, um caminho, uma estratégia que possibilite construir um conhecimento interpretativo sobre o homem, a sociedade, a educação, suas relações entre si e dessas com o mundo físico e natural. A premissa é aspirar a um saber não-fragmentado, não-compartimentado, não-redutor, e o reconhecimento do inacabado e da incompletude de qualquer conhecimento (MORIN, 2005a). Há um conjunto de princípios metodológicos que configuram e orientam um pensar complexo:

O Princípio sistêmico ou organizacional possibilita religar o conhecimento das partes com o conhecimento do todo e vice-versa. Do ponto de vista sistêmico organizativo o todo é mais do que a soma das partes. Essa expressão "mais" apresenta fenômenos qualitativamente novos (qualidades e propriedades) que são denominados de "emergências". Esses fenômenos são produtos da organização proveniente da interação dinâmica das partes dentro da unidade sistêmica. Conforme salienta Morin (2005a, p.86): 
[...] a tapeçaria é mais do que a soma dos fios que a constituem. Um todo é mais do que a soma das partes que o constituem. Nessa tapeçaria, como na organização, os fios não estão dispostos ao acaso. Eles são organizados em função de um roteiro, de uma unidade sintética onde cada parte contribui para o conjunto.

O Princípio hologramático indica que as partes contêm quase todas as informações do objeto que representam. As informações da parte estão no todo, bem como o todo está inscrito em cada parte do sistema. "[...] cada um de nós, como indivíduos, trazemos em nós a presença da sociedade da qual fazemos parte. A sociedade está presente em nós por meio da linguagem, da cultura, de suas regras, normas, etc.” (MORIN; CIURANA; MOTTA, 2003, p.34).

$\mathrm{O}$ Princípio de retroatividade aponta para a necessidade de superação da causalidade linear. A causa age sobre o efeito e o efeito age sobre a causa (MORIN, 2001a). É o princípio que indica mecanismos por meio dos quais todo sistema tem de permanecer em equilíbrio dinâmico, ou seja, há fluxos de dispersão de energia e fluxos de captação de matéria, informação e energia do mundo externo e/ou de outros sistemas que o fazem manter-se "vivo". São fenômenos inflacionadores ou estabilizadores.

O Princípio de recursividade é um circuito gerador em que os produtos e os efeitos gerados por um sistema tornam-se os produtores e causadores daquilo que os produz. Pode-se chamar de causalidade complexa, na qual cada momento "final" "[...] é sempre um novo começo e cada início emerge de um final anterior e o movimento cresce em espiral" (MORAES, 2004b, p.2). É uma dinâmica autoprodutiva e auto-organizacional. É um processo no qual os efeitos ou produtos são, simultaneamente, causadores e produtores do próprio processo (produz-se e reproduz-se) (MORIN; CIURANA; MOTTA, 2003).

O Princípio da autonomia/dependência promove a idéia de que os sistemas apresentam um processo auto-eco-organizador. Para manter a autonomia, qualquer organização precisa de interação com o ecossistema do qual se nutre. Assim, os seres vivos não param de se autoproduzir, o que demanda interação com o meio ambiente, seja ele biológico, cultural ou social (MORIN, 2001a) na transferência de energia, matéria e informação. Portanto, sua autonomia existe na medida de sua dependência com as fontes de manutenção de sua própria autonomia. Para Morin (2001a, p.95) "[...] os humanos desenvolvem sua autonomia na dependência de sua cultura [...] Nossa autonomia como indivíduos não só depende da energia que captamos biologicamente do ecossistema, mas da informação cultural".

O Princípio dialógico é um princípio que pode ser entendido como uma 
associação complexa (complementar/concorrente/antagônica) de dimensões da realidade física, natural ou social que convivem e concorrem para que determinado fenômeno exista e se desenvolva, embora sejam antagônicos. Não se pode pensar o ser humano sem conceber a dialógica: sapiens/demens. "É impossível pensar a sociedade reduzindo-a aos indivíduos ou à totalidade social; a dialógica entre indivíduo e sociedade deve ser pensada num mesmo espaço" (MORIN; CIURANA; MOTTA, 2003, p.36-37). Mantém-se a dualidade no âmbito de uma unidade, associando-se ao mesmo tempo, termos complementares e antagônicos (MORIN, 2005a). Concebem-se processos organizadores, produtivos e criadores no mundo complexo da história e vida humanas, levando-se em conta a tensão dialógica entre as dimensões que se associam com aquelas que se contrapõem.

O Princípio da (re)introdução do sujeito cognoscente em todo conhecimento recupera o papel do sujeito e aponta para a centralidade que o indivíduo tem na teorização científica à medida que o espírito(mente) do sujeito está enraizado numa cultura e num dado tempo histórico e, portanto, o conhecimento não será um reflexo do real, mas fruto de sua interpretação. Para Morin (1993, p.93) "O pensamento humano é algo de singular, bizarro no universo; ele não reflete o real, ele o traduz, não reflete o mundo, faz uma representação dele".

\section{Diálogos preliminares}

Com efeito, a Pedagogia produz um saber científico a partir da prática educativa, reconhecendo-se que no âmbito do ato pedagógico se produzem saberes enraizados à cultura educativa que dinamizam as relações entre os atores educativos; que norteiam os processos de ensino e de aprendizagem; saberes criados e indissociáveis na relação entre educador e educando.

Conforme Houssaye et al. (2004), a Pedagogia está indissoluvelmente ligada à prática. Contudo, isso não lhe faz ficar cega ou domiciliada ao senso comum, mas procura elaborar um conhecimento pedagógico para além dos saberes práticos. A produção desse conhecimento pedagógico, fruto do diálogo entre um conhecimento teórico e os saberes pedagógicos inscritos no Irredutível Pedagógico (ESTRELA, 1980 apud PIMENTA, 1996), se traduzirá por meio de um método necessário para disciplinar e dirigir a sistematização do conhecimento científico.

Os diálogos preliminares entre a Pedagogia e a teoria da complexidade não irão se esgotar aqui, mas iniciam-se com vistas a possibilitar uma incorporação 
dialógica das contribuições trazidas pelos grandes debates paradigmáticos das ciências do homem e da natureza (ciências físicas - da microfísica à astrofísica, as ciências biológicas - da genética e da biologia molecular à etologia, da antropologia) à ciência que trata dos processos educativos.

Uma perspectiva teórica de diálogo pode ser iniciada quando a teoria da complexidade estabelece a concepção sistêmico-organizacional como um de seus princípios para compreender e interpretar a realidade complexa. A teoria da complexidade pode contribuir para que o escopo da Pedagogia em relação à organização escolar se amplie numa perspectiva sistêmica, o que significa pensar, epistemologicamente, que o fenômeno educativo (escolar e não-escolar) deve ser observado e interpretado em nível de conhecimento científico a partir das relações inter-retro-organizacionais.

Incorporado à Pedagogia como um princípio teórico e metodológico de análise e interpretação da realidade educativa (escolar e não-escolar), a concepção sistêmico-organizacional do fenômeno educativo implicará no entendimento da relação do todo com as partes e das particularidades das partes com o todo, numa inter-relação, numa interdependência, numa articulação entre os elementos constituintes (partes) de uma organização escolar (todo) e suas características e propriedades particulares.

A complexidade do trabalho pedagógico escolar (ou não-escolar) não poderá ser vista tomando-se um aspecto, um elemento e/ou suas características ou propriedades isoladamente. $\mathrm{O}$ trabalho pedagógico escolar (ou não-escolar) será percebido, em nível de conhecimento pedagógico, quando se explora e analisa o todo, percorrendo dinamicamente seu processo de constituição, de construção e de desenvolvimento, bem como e, ao mesmo tempo, explorando e analisando as particularidades das partes, dos seus elementos constituintes e de suas possibilidades e limitações, as quais, dialética e dialogicamente, remetemse ao trabalho pedagógico escolar (ou não-escolar).

O fenômeno educativo (escolar e não-escolar), concebido como uma organização sistêmica, pode ser interpretado pela Pedagogia da seguinte forma: professores, estudantes, equipe pedagógica e equipe de apoio técnico-administrativo estão interligados e estabelecem relações de interação e interdependência. A ação de um dos elementos constituintes do ato pedagógico (escolar ou nãoescolar) interfere na atividade de outro e vice-versa. Pelo princípio recursivo pode-se inferir que no âmbito do real pedagógico se constrói uma trama na qual é inadequado se pensar em "culpados" ou "inocentes". A complexidade vai ensinar que o maniqueísmo entre o bem e o mal, o culpado e o salvador, tratase de um pensamento reducionista que não contempla a dialeticidade do real, da ambigüidade existente na ação pedagógica, de toda a incerteza pertinente e pertencente às ações do homem (MORIN, 2002a). 
A complexidade permite à Pedagogia "ver" que os fenômenos educativos complexos são processuais, inacabados e transitórios, assim como as interações entre os agentes pedagógicos da organização educativa. Rompe-se com uma causalidade linear e busca-se uma causalidade complexa. Identifica-se um anel recursivo no processo educativo (escolar e não-escolar) no qual as ações retroagem umas sobre as outras, realimentando-as e modificando-as (MORAES, 2007).

A Resolução n. 01/2006 - CNE/CP, no artigo $3^{\circ}$, parágrafo único, item I, quando trata a respeito da investigação da Pedagogia diz que: "[...] o conhecimento da escola como organização complexa [grifo nosso] que tem a função de promover a educação para e na cidadania" (BRASIL, 2006). Para que a escola venha a cumprir este papel é preciso compreender que seus agentes pedagógicos são seres humanos que estabelecem relações humanas complexas que vão além das relações profissionais de trabalho. Tanto docentes quanto estudantes são indivíduos multidimensionais, ou seja, são ao mesmo tempo: biológicos, psíquicos, sociais, afetivos, racionais, passionais, míticos etc. O ser humano é sapiens/demens (MORIN, 2000, 2002b, 2002c, 2003, 2005a, 2005b). Tudo isso tem sérias implicações na práxis educativa e na produção do conhecimento científico pedagógico.

A organização escolar, pela ótica do princípio sistêmico-organizacional, revela que sua singularidade organizativa complexa é constituída de múltiplas dimensões: econômica, cultural, religiosa, mítica, política, social, antropológica, tecnológica, geográfica, histórica, educacional, científica, biológica e etc., nas quais todas concorrem, cooperam e se interpenetram num processo dialógico e dialético no qual, ao mesmo tempo em que são contraditórias e antagônicas, são complementares.

\section{REFERÊNCIAS}

ALMEIDA, M.C.X. Educar para a complexidade: o que ensinar, o que aprender. Curitiba (PR): Secretaria Municipal da Educação de Curitiba/Departamento de Tecnologia e Difusão Educacional, Semana de Estudos Pedagógicos, 2005, p.16. Mimeografado.

BRASIL. CONSELHO NACIONAL DE EDUCAÇÃO -CNE. Resolução CNE/CP n. 01/2006, de 15 de maio de 2006. Institui as Diretrizes Curriculares Nacionais para o Curso de Graduação em Pedagogia, licenciatura. 
BEHRENS, M. A. Paradigma da complexidade - metodologia de projetos, contratos didáticos e portfólios. Petrópolis: Vozes, 2006.

BRZEZINSKI, I. Pedagogia, pedagogos e formação de professores. Campinas: Papirus, 1996.

CAPRA, F. As conexões ocultas: ciência para uma vida sustentável. São Paulo: Cultrix, 2002.

CARVALHO, E. de A. Enigmas da cultura. São Paulo: Cortez, 2003.

FERREIRA, A. B. de H. Novo dicionário da língua portuguesa. 2. ed. Rio de Janeiro: Nova Fronteira, 1986.

FREITAS, L.C. Notas sobre a especificidade do pedagogo e sua responsabilidade no estudo da teoria e prática pedagógicas. Educação de Sociedade, São Paulo: Cortez, n. 22, p.12-19, 1985.

FRANCO, M. A. S. Pedagogia como ciência da educação. Campinas: Papirus, 2003.

FRANCO, M. A. S. et al. Elementos para a formulação de diretrizes curriculares para cursos de Pedagogia. Cadernos de Pesquisa, São Paulo, v. 37, n. 130, p.63-97, jan./ abr. 2007.

GIDDENS, A. Modernidade e identidade. Tradução: Plínio Dentzien. Rio de Janeiro: Jorge Zahar, 2002.

HOUSSAYE, J. et al. Manifesto a favor dos pedagogos. Tradução: Vanise Dresch. Porto Alegre: Artmed, 2004.

LIBÂNEO, J. C. Que destino os educadores darão à pedagogia? In: PIMENTA, S.G. (Org.). et al. Pedagogia, ciência da educação? São Paulo: Cortez, 1996.

. Pedagogia e pedagogos, para quê? São Paulo: Cortez, 1998.

. Diretrizes curriculares da pedagogia: imprecisões teóricas e concepção estreita da formação profissional de educadores. Educação e Sociedade, Campinas, v. 27, n. 96 (especial), p.843-876, out. 2006. Disponível em: <http://www.cedes.unicamp.br>.

. A pedagogia em questão: entrevista com José Carlos Libâneo. Olhar de Professor, Ponta Grossa, n. 10(1), p.11-33, 2007.

MORAES, M. C. O paradigma educacional emergente. 4. ed. Campinas: Papirus, 1997. 
Pensamento eco-sistêmico: educação, aprendizagem e cidadania no século XXI. Petrópolis: Vozes, 2004a.

; TORRE, S. L. Sentipensar: fundamentos e estratégias para reencantar a educação. Petrópolis: Vozes, 2004b.

. A formação do educador a partir da complexidade e da transdisciplinaridade. Diálogo Educacional, Curitiba, v. 7, n. 22, p. 13-38, set./dez. 2007.

MORIN, E. Contrabandista dos saberes. In: PESSIS-PASTERNAK, G. Do caos à inteligência artificial. 4. ed. Tradução: Luiz Paulo Rouanet. São Paulo: Editora UNESP, 1993.

. Os sete saberes necessários à educação do futuro. Tradução de Catarina Eleonora F. da Silva e Jeanne Sawaya. Revisão técnica de Edgar de Assis Carvalho. São Paulo: Cortez; Brasília, DF: UNESCO, 2000.

. A cabeça bem-feita: repensar a reforma, reformar o pensamento. Tradução: Eloá Jacobina, 5. ed. Rio de Janeiro: Bertrand Brasil, 2001a.

. Ciência com consciência. Tradução: Maria D. Alexandre e Maria Alice Sampaio Dória. 5. ed. Rio de Janeiro: Bertrand Brasil, 2001b.

. Em busca dos fundamentos perdidos - textos sobre o marxismo. Tradução: Maria Lúcia Rodrigues e Salma Tannus. Porto Alegre: Sulina, 2002a.

. A religação dos saberes - o desafio do século XXI. Tradução: Flávia Nascimento. 3. ed. Rio de Janeiro: Bertrand Brasil, 2002b.

. O método 5: a humanidade da humanidade - identidade humana. Tradução de Juremir Machado da Silva. Porto Alegre: Sulina, 2002c.

. Amor, poesia e sabedoria. Tradução Edgar de Assis Carvalho. 6. ed. Rio de Janeiro: Bertrand Brasil, 2003.

. Introdução ao pensamento complexo. Tradução: Eliane Lisboa. Porto Alegre: Sulina, 2005a.

. O método 6: ética. Tradução: Juremir Machado da Silva. Porto Alegre: Sulina, $2005 \mathrm{~b}$.

MORIN, E.; CIURANA, E. R.; MOTTA, R. D. Educar na era planetária.Tradução: Sandra T. Valenzuela. Revisão técnica: Edgard de Assis Carvalho. São Paulo: Cortez; Brasília, DF: UNESCO, 2003. 
PENA-VEGA, A. et al. (Org.). Edgar Morin: ética, cultura e educação. São Paulo: Cortez, 2001.

PETRAGLIA, I. C. Edgar Morin: complexidade, transdisciplinaridade e incerteza. Curitiba: Secretaria Municipal da Educação de Curitiba/Departamento de Tecnologia e Difusão Educacional, Semana de Estudos Pedagógicos, 2005, p.13. Mimeografado.

PIMENTA, S. G. (Org.). Pedagogia, ciência da educação? São Paulo: Cortez, 1996. 2002. . (Org.). Pedagogia e pedagogos: caminhos e perspectivas. São Paulo: Cortez,

PRIGOGINE, I. As leis do caos. Tradução: Roberto Leal Ferreira. São Paulo: Editora UNESP, 2002.

RODRIGUES, Z. L. Ciência, filosofia e conhecimento: leituras paradigmáticas. Palmas(PR): Kaygangue, 2003.

SA, R. A. A construção do pedagogo - Superando a fragmentação do saber: uma proposta de formação. 1997. 155 f. Dissertação de Mestrado - Programa de Pós-Graduação em Educação, Universidade Federal do Paraná, Curitiba, 1997.

. Pedagogia: identidade e formação - o trabalho pedagógico nos processos educativos não escolares. Educar em Revista, Curitiba: Editora UFPR, Setor de Educação, n. 16, p. 171-180, 2000.

. Contribuição para uma concepção de formação unitária do pedagogo escolar tomando o trabalho pedagógico escolar como seu princípio educativo. Máthesis - Revista de Educação, Jandaia do Sul (PR), v. 7, n. 2, p. 57-93, jul./dez. 2006.

SCHMIED-KOWARZIK, W. Pedagogia dialética: de Aristóteles a Paulo Freire. São Paulo: Brasiliense, 1983.

SILVA, Carmem Silva Bissolli da. Curso de Pedagogia na Brasi: história e identidade. Campinas: Autores Associados, 1999.

Texto recebido em 05 de maio de 2008 . Texto aprovado em 30 de junho de 2008. 